\title{
Effect of Prenatal Zinc Supplementation on Birthweight
}

\author{
Mahama Saaka, Jacques Oosthuizen, and Shelley Beatty \\ School of Exercise, Biomedical and Health Sciences, Edith Cowan University, \\ 100 Joondalup Drive, Joondalup, WA 6027, Australia
}

\begin{abstract}
Although iron and zinc deficiencies are known to occur together and also appear to be high in Ghana, a few supplementation studies addressed this concurrently in pregnancy. In a double-blind, randomized controlled trial, 600 pregnant women in Ghana were randomly assigned to receive either a combined supplement of $40 \mathrm{mg}$ of zinc as zinc gluconate and $40 \mathrm{mg}$ of iron as ferrous sulphate or $40 \mathrm{mg}$ of elemental iron as ferrous sulphate. Overall, there was no detectable difference in the mean birthweight between the study groups, although the effect of iron-zinc supplementation on the mean birthweight was masked by a strong interaction between the type of supplement and the iron status of participants [F $(1,179)=5.614, p=0.019]$. Prenatal iron-zinc supplementation was effective in increasing the mean birthweight among anaemic and iron-deficient women but not among women with elevated iron stores in early pregnancy.
\end{abstract}

Key words: Birthweight; Double-blind method; Impact studies; Prospective studies; Randomized controlled trials; Iron supplementation; Zinc supplementation; Ghana

\section{INTRODUCTION}

Analysis of birthweight data collected from major hospitals in the Upper West Region of Ghana showed that the incidence of low birthweight (LBW) ranged from $15.0 \%$ to $29.1 \%$ (1). Birthweight has a significant influence on the growth and development of a child (2-5). Furthermore, several studies have identified LBW as an important risk factor for neonatal and infant mortality and impaired postnatal growth (6-8). Unfortunately, LBW continues to affect a large proportion of infants, especially in developing countries, and is associated with high prevalence of chronic child undernutrition in these countries (9). This is a major challenge to the attainment of Millennium Development Goals (MDGs), because adequate nutrition is critical to achieving the MDGs, especially goal four which aims at reducing by two-thirds of the mortality rate among

Correspondence and reprint requets should be addressed to:

Dr. Mahama Saaka

School of Exercise, Biomedical and Health Sciences Edith Cowan University

100 Joondalup Drive

Joondalup, WA 6027

Australia

Tel: 23375622016

Email: mahamasaaka@yahoo.com

Fax: 23375622471 children aged less than five years by 2015 (10). Malaria and maternal anaemia continue to be significant public-health problems in pregnancy, especially in developing countries $(11,12)$. To reduce these problems in Ghana, pregnant women who attend antenatal care services are given sulphadoxine pyrimethamine as chemoprophylaxis for malaria together with iron and folic acid but without zinc supplements. However, proxy indicators, which reflect zinc deficiencies strongly, suggest that the risk of zinc deficiency in Ghana may be high. Ghana is classified to be in the medium risk category in terms of zinc deficiency based on the prevalence of stunting (25.9\%) and the estimated proportion of the population at risk of inadequate zinc intake (21.0\%) by the International Zinc Nutrition Consultative Group Steering Committee (IZiNCG SC) (13).

Zinc deficiency impairs the immune function and resistance to infections (14). Zinc-deficient pregnant women resident in malaria-endemic areas may, therefore, be more predisposed to reduced resistance to malarial infections. Improved maternal zinc status through maternal supplementation may boost naturally-acquired immunity against malarial infection during pregnancy, thereby reducing its adverse consequences on foetal growth. Zinc-only supplementation against malaria in pregnancy may not be feasible since iron is already given rou- 
tinely to women who attend antenatal care services in most developing countries. Furthermore, the absence of evidence regarding the effectiveness of zinc-alone supplementation could be as a result of methodological and analytical flaws, or that some other unidentified limiting factors need to be addressed concurrently. In particular, although the inhibitory nature of iron and zinc in aqueous solutions has been studied, the effect of maternal iron status on the supplementation of these nutrients is unclear. Furthermore, although empirical evidence suggests that iron and zinc deficiencies often occur together $(15,16)$ and may impact on pregnancy outcomes, a few supplementation studies have addressed this concurrently in pregnancy (17). Consequently, a combined effect of iron and zinc on birthweight merits further investigation.

\section{Hypotheses}

Prenatal zinc supplementation, in combination with a malaria prophylaxis, iron and folic acid intervention package in a zinc-deficient and malariaendemic population, will increase the mean birthweight.

The secondary hypothesis was prenatal iron-zinc supplementation as an adjunct to chemoprophylaxis with sulphadoxine pyrimethamine will (a) increase plasma zinc and iron concentrations, (b) increase length of gestation, and (c) reduce incidence of LBW, intrauterine growth restriction (IUGR), and preterm delivery.

\section{MATERIALS AND METHODS}

\section{Study design}

A prospective double-blind, randomized controlled trial was conducted in the Upper West Region of Ghana from September 2005 to November 2006. In this two-arm design, the iron-zinc group received a combined supplement of $40 \mathrm{mg}$ of zinc as zinc gluconate and $40 \mathrm{mg}$ of iron as ferrous sulphate. The control group received $40 \mathrm{mg}$ of iron as ferrous sulphate. Both the groups also received chemoprophylaxis for malaria with sulphadoxine pyrimethamine, and $400 \mu \mathrm{g}$ of folic acid. The iron and zinc supplements were taken every other day from enrollment until delivery. The iron supplement given to participants in the control group was packaged exactly as the iron-zinc supplement.

\section{Study participants}

The study population comprised pregnant women who presented themselves for antenatal care (ANC) in the Wa Regional Hospital of the Upper West Re- gion in Ghana. The inclusion criteria for the recruitment of participants were all pregnant women who had earlier been assessed through ultrasonography and found to be no more than the 16-week period of gestation. Women were excluded if they were identified through interviews to be on any other form of zinc supplements at any dosage or were severely anaemic, i.e. haemoglobin $(\mathrm{Hb})$ less than $7.0 \mathrm{~g} / \mathrm{dL}$.

Eligible women for the study gave a free and informed consent before enrollment. The investigator explained, in the local dialect, the purpose and aims of the study to each potential participant. Women who agreed to participate in the study signed/thumb-printed the consent form and those who consented were given copies of the signed consent form. After enrollment, each participant was given a unique serial number, and this was recorded on her antenatal care card.

Ethical clearance for the study was approved by the Edith Cowan University (ref. 04-276) and Ghana Health Service Ethical Review Committee (ref. GHS-ERC-3).

\section{Randomization}

Participants were randomly assigned to one of the two study groups. An independent statistician generated the allocation schedule/sequence using computer-generated random numbers using the Excel software. After obtaining informed consent for enrollment, the midwife assigned participants in blocks of hundreds until the required sample size was met. There was no stratification during the randomization.

\section{Concealment of random allocation sequence}

The assignment of participants to study conditions was administered at the study centre. The treatment allocations generated were put in opaque envelopes and serially numbered. Each envelope contained a card on which the specific treatment was indicated. To safeguard the allocation schedule/sequence, envelopes were opened sequentially and only after the participant's name and other details were written on the envelope. The statistician who generated the allocation schedule kept the schedule that contained the random allocations until the collection of data was completed.

\section{Blinding}

The iron-zinc and iron-only supplements were precoded and supplied by the Nutricaps Pharmaceutical Company, USA. The supplements (in the form 
of capsules) were of the same shape, colour, and taste.

\section{Administration of supplements and monitoring of compliance}

Each enrolled participant was instructed how to take the supplements, i.e. dosage and frequency. Participants were advised to take the supplements at least two hours before or after meals, and this translated practically to taking the supplements at night, just before going to bed, i.e. in the postabsorptive state. Each participant was supplied with enough supplements to last for two months at a time. Participants visited the hospital for antenatal care every four weeks. On these visits, they brought along the remainder of supplements supplied to them to monitor compliance by the research staff. Compliance/adherence was monitored by interviewing the participants after having being enrolled for four weeks. A structured questionnaire was administered at home to check the frequency and dosage of intake of the supplement. The degree of compliance was measured in terms of the total number of capsules taken during the trial period. The fundamental elements that underlined full compliance included taking the correct dosage and frequency at the appropriate time, i.e. one capsule every other day in the post-absorptive stage.

\section{Data collection}

The blood samples analyzed for zinc were collected and plasma separated, stored at-34 ${ }^{\circ} \mathrm{C}$ until these were transported for analysis at the Ghana Nuclear Research Institute in November 2006. On the first antenatal care visit and at 34-36 weeks of gestation, a trained laboratory technologist collected fasting (more than 8 hours) venous blood samples $(5 \mathrm{~mL})$ from all the study participants. All fasting blood samples for analysis of plasma zinc were collected in the morning before 11.00 am to avoid diurnal variation in plasma zinc during the day. The fasting blood sugar level for each subject was also tested to make sure of the fasting state of the participant. The blood was collected into trace mineral-free EDTA bottles and refrigerated immediately until the plasma separated. Blood serum which was analyzed for ferritin was, however, separated from the cellular blood components using trace element-free techniques. Samples were stored, frozen at $-34{ }^{\circ} \mathrm{C}$ and later transported by road for analysis.

The primary outcome variable was birthweight. The secondary end-points included, $\mathrm{Hb}$, serum ferritin, plasma zinc concentrations, and length of gesta- tion. Serum ferritin data were available for a subsample of 213 women at recruitment, 173 of these were repeated at 34-36 weeks gestation because of the inability to assess them at the scheduled time. Data for the assessment of zinc status were available for a subgroup of 100 women at recruitment and repeated for 86 of them at 34-36 weeks of gestation. Malarial infection was also assessed at recruitment and in late pregnancy. Only participants who had a complete set of data were finally included in the analysis.

The dependent variables, therefore, included the following: (a) mean birthweight, (b) mean and changes in serum ferritin concentration, (c) mean and percentage changes in plasma zinc concentration, (c) length of gestation, and (d) incidence of LBW, IUGR, and preterm delivery.

Maternal height was measured on the first visit of the participant to the antenatal care clinic. Height was measured to the nearest $0.1 \mathrm{~cm}$ using a stadiometer. The Seca 767 digital adult scale was used for weighing the participants to the nearest 0.05 $\mathrm{kg}$ at recruitment, 28 weeks of gestation, and 3436 weeks of gestation. Body mass index (BMI) was calculated automatically using the Seca 767 digital adult scale. Height of each participant in centimetre was entered into the scale with the BMI function made operational.

The blood pressure of the participants was measured at recruitment, 28 and 36 weeks of gestation by trained midwives, following standard procedures.

A trained gynaecologist assessed gestational age at recruitment of participants on their first visit to the antenatal care clinic. In view of recall bias associated with the last menstrual period (LMP) approach, gestational age of the newborn was assessed using biometric measurements of the foetus, i.e. ultrasound scanning. This assessment was done early in pregnancy (16-18 weeks). The dates for the assessment of gestational age at recruitment and at delivery were all recorded in a pre-designed datacollection form. The length of gestation was subsequently calculated in completed weeks from the recorded data.

Babies delivered in the hospital were weighed naked within three hours of delivery using accurate and sensitive baby scales (Seca 334, Germany). The trained midwives recorded birthweight to the nearest $1.0 \mathrm{~g}$. The newborns were classified using the California Foetal Reference Curves recommended by the World Health Organization (WHO) (18). 
Fasting blood samples were collected at baseline and at 34-36 weeks of gestation from the participants to measure haemoglobin, serum ferritin, and plasma zinc. Concentration of haemoglobin was measured by the cyanmethemoglobin method $(19,20)$. Serum ferritin was measured using a microparticle enzyme immunoassay on the Abbott AxSym chemistry analyzer (Abbott Laboratories, Abbott Park, Illinois, USA). (21). Flame atomic absorption spectrophotometry (AAS) (Varian Model AA 200, South Africa) was used for quantifying plasma zinc following a standardized procedure (22).

Two hospital laboratory technologists diagnosed peripheral blood parasitaemia through microscopic examination of thin and thick blood smears. Malaria parasite and leukocytes counts were made on the same microscopic fields, and a minimum of 200 leucocytes was counted in each blood sample. Blood-films were classified as negative if no asexual form of Plasmodium falciparum was detected under 100x magnifications.

Status of HIV was determined by the rapid test for HIV-1 and 2 and Determine HIV1/2 (23). Sociodemographic and other information were collected in the third trimester using a structured questionnaire.

\section{Calculation of sample size and sampling procedure}

With two-sided hypothesis testing, the probability of committing type I (false-positive) and type II (false-negative) errors was set at alpha=0.05 and beta $=0.2$ respectively. The estimated effect size was $150 \mathrm{~g}$. The natural variability (standard deviation) of the mean birthweight calculated from birthweight data collected from the study population prior to this study was $580 \mathrm{~g}$. So, the required sample size (n) for each study group was calculated following a standard formula $(24,25)$.

The required sample size large enough to detect a reliable smallest difference in the primary outcome was 470 . Allowing for a $15 \%$ loss to follow-up and about $2 \%$ multiple births, i.e. 41 women, the estimated sample size per group was 300 . The overall sample was adjusted to 600 pregnant women.

\section{Data management and analyses}

Data were collected on pre-designed forms and registers and edited in the field for completeness and consistency before entry into a computer for analysis. The data were coded for statistical analysis using the SPSS software for Windows (version 14.0) (SPSS Inc, Chicago, IL, USA).
Before formal statistical tests were applied, the dataset was explored to verify whether conditions for parametric tests were met, e.g. normality and homogeneity of variance. Data that failed the normality test were log-transformed before a parametric test could be used. Effect modification and confounding were identified and adjusted for during data analysis through stratified and/or multivariate analyses. An interaction analysis was used for investigating subgroup effects between treatment and maternal iron status, and the treatment effect was presented by substrata. The rationale behind this lies with the fact that whenever interaction is present, strata-specific estimates instead of summary measures of association are to be reported (26). The investigators had suspected this kind of interaction right from the design stage because several studies reported high maternal iron stores and especially when supplemented with iron during pregnancy resulted in adverse pregnancy outcomes (27-30).

As the dataset included some repeated measures (for example, density of parasites, serum ferritin, and zinc), analysis of covariance (ANCOVA) was used for determining the post-test differences between the treatment groups. ANCOVA was also used for adjusting group means because some outcomes, e.g. birthweight, were influenced by multiple prognostic factors. Multiple regression analysis was also used for determining the minimum set of variables that accounted for the proportion of variance of the primary outcome measure, i.e. mean birthweight.

Multivariate logistic modelling technique was performed to determine the set of risk factors that predicted the mean birthweight and the risk of LBW $(<2,500)$, IUGR (birthweight below the $10^{\text {th }}$ percentile), and premature delivery ( $<37$ weeks). Statistical difference was considered significant if the $\mathrm{p}$ value was $<0.05$, and $95 \%$ confidence intervals (CIs) were calculated for all main outcome measures.

\section{RESULTS}

\section{Sample characteristics}

The mean age of the study participants at recruitment was $27 \pm 5.4$ years with a range of $16-44$ years. The baseline maternal characteristics, including nutritional indicators, to compare the study groups are presented in Table 1 . The mean gestational age at recruitment was $13.0 \pm 3.0$ completed weeks. The study groups did not differ significantly in terms of their baseline characteristics, except for age where the iron-zinc group had older participants [F $(1,598)=4.864, \mathrm{p}=0.028)]$ (Table 1). 


\begin{tabular}{|c|c|c|c|c|}
\hline \multirow[t]{2}{*}{ Characteristics } & \multicolumn{2}{|c|}{$\begin{array}{l}\text { Control group } \\
(\mathrm{n}=301)\end{array}$} & \multicolumn{2}{|c|}{$\begin{array}{l}\text { Iron-zinc group } \\
\quad(\mathrm{n}=299)\end{array}$} \\
\hline & Mean & SD & Mean & SD \\
\hline Maternal age (years) & 26.4 & 5.0 & 27.4 & 5.6 \\
\hline $\begin{array}{l}\text { Geometric mean density of malaria parasite (parasites/ } \\
\mu \mathrm{L} \text { blood) }\end{array}$ & 464.0 & 3.0 & 342.0 & 4.0 \\
\hline Geometric mean concentration of plasma zinc $(\mu \mathrm{g} / \mathrm{dL})$ & 26.4 & 2.5 & 26.2 & 2.5 \\
\hline $\mathrm{Hb}$ concentrations $(\mathrm{g} / \mathrm{dL})$ & 11.3 & 1.5 & 11.2 & 1.4 \\
\hline Geometric mean concentration of serum ferritin $(\mu \mathrm{g} / \mathrm{L})$ & 33.2 & 2.4 & 34.8 & 2.3 \\
\hline Maternal height $(\mathrm{cm})$ & 159.1 & 5.6 & 159.2 & 6.0 \\
\hline Maternal weight (kg) & 63.2 & 12.1 & 63.1 & 10.9 \\
\hline Body mass index $\left(\mathrm{kg} / \mathrm{m}^{2}\right)$ & 25.0 & 4.5 & 25.0 & 4.0 \\
\hline Gestational age at recruitment (weeks) & 13.7 & 2.9 & 13.8 & 2.9 \\
\hline Diastolic blood pressure (mm Hg) & 59.0 & 10.0 & 59.0 & 10.0 \\
\hline Systolic blood pressure (mm Hg) & 103.5 & 12.7 & 102 & 13.2 \\
\hline Parity & 1.41 & 1.55 & 1.64 & 1.89 \\
\hline
\end{tabular}

\section{Follow-up and compliance with supplements}

The number of participants recruited, enrolled, and loss-to-follow-up is shown in the Figure.

The total loss-to-follow-up rate was 9.5\%; this was less than $10.0 \%$ and was, therefore, not a threat to the validity and power of the study. In total, 9.0\% $(n=27)$ of the participants $(n=299)$ were lost-to-follow-up in the zinc-supplemented group compared to $9.9 \%(n=30)$ of the participants $(n=301)$ in the control group. The minimum total sample size required to detect the $150 \mathrm{~g}$ mean birthweight difference at $80 \%$ power was calculated to be 470 , and 543 participants completed the study.

Pregnancy loss, i.e. miscarriages, spontaneous abortions, and stillbirths, accounted for $45.6 \%(n=26)$ of the participants who were lost-to-follow-up, and $1.3 \%(\mathrm{n}=7)$ of the total deliveries $(\mathrm{n}=550)$ were multiple births. In addition, $4.0 \%(\mathrm{n}=24)$ of the total number of randomized participants were lost at dif-

Fig. A flow diagram showing the number of participants recruited, randomized, and lost-to-follow-up

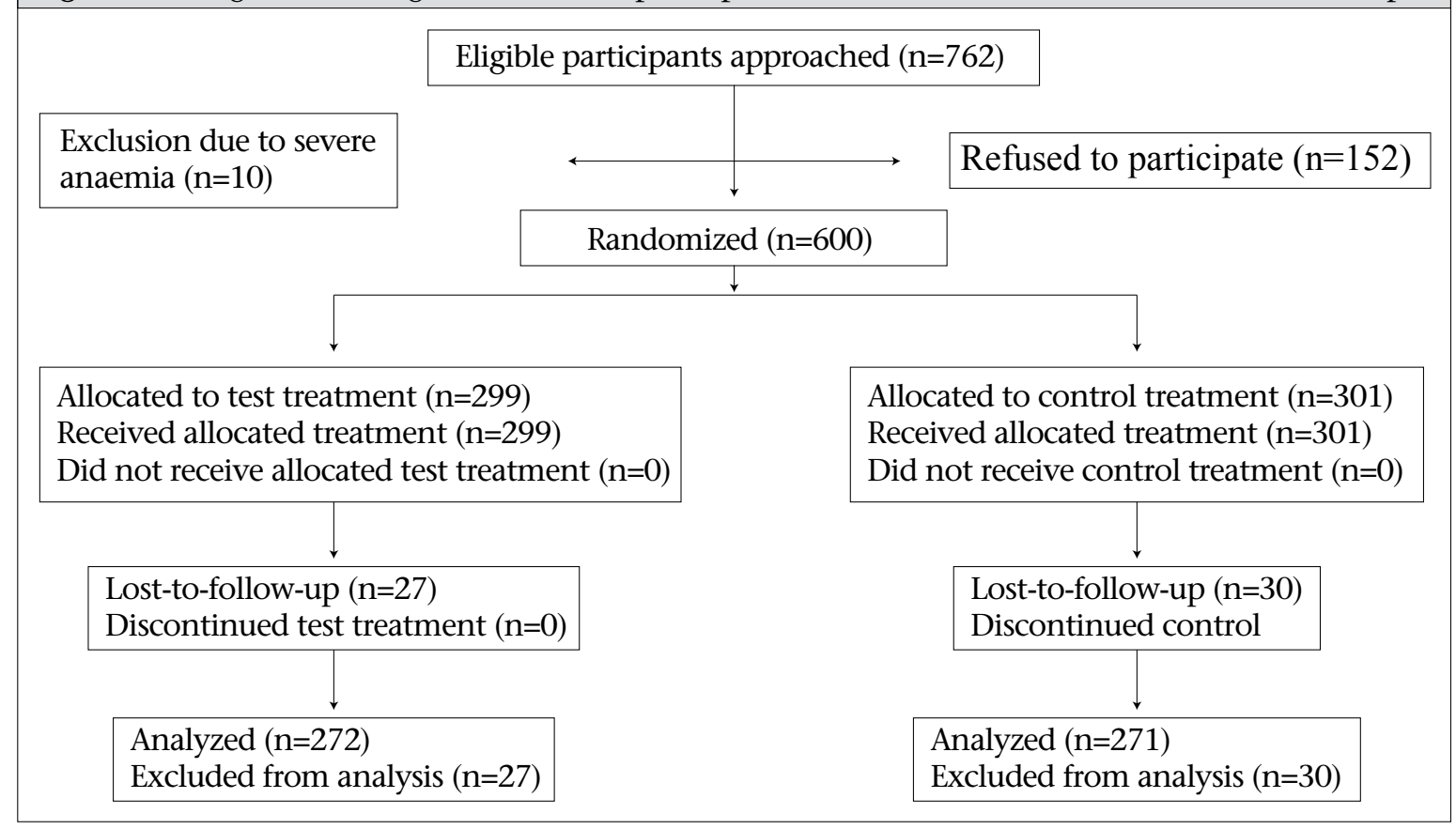


ferent stages of the trial as they travelled out of the study area and could not be traced.

There were no differences in the compliance levels between the study groups. Full compliance/adherence in the study was generally high and was measured in terms of dosage, time, and frequency of taking the supplements. Partial compliance meant that a participant did not take her supplement at the prescribed time, dosage, or frequency. The degree of compliance was measured in terms of the total number of capsules taken during the trial period.

Of the participants enrolled, 91.7\% $(n=550)$ delivered, and seven of the women delivered twins. There were, therefore, 543 singleton livebirths; $49.8 \%(n=269)$ were males, and 50.2\% $(n=271)$ were females. Of the 543 singleton livebirths, $91.5 \%$ $(n=497)$ were by spontaneous vaginal delivery (SVD) and $8.5 \%(n=46)$ by caesarean section.

\section{Effect of iron-zinc supplementation on pregnancy outcomes}

Overall, there was no detectable difference in the mean birthweight between the study groups. The adjusted mean birthweight in the iron-zinc group was $3,105 \pm 490 \mathrm{~g}$ and in the control group was $3,120 \pm 486 \mathrm{~g}$. However, adjusted for gestational weight gain between week 28 and week 36 , diastolic pressure at 34-36 weeks of gestation, gender of baby, IUGR, preterm delivery, length of gestation, maternal weight, and gravidity through ANCOVA analysis, an interaction between maternal iron status at recruitment and treatment type manifested $[\mathrm{F}(1,179)=5.614, \mathrm{p}=0.019]$. Consequently, adjusted for diastolic pressure at 34-36 weeks of gestation, gender of baby, gestational weight gain between 28 and 36 weeks of gestation, IUGR, length of gestation, preterm delivery, and BMI, the adjusted mean birthweight of babies born to women in the ironzinc group was $131 \mathrm{~g}$ higher than the adjusted mean birthweight of babies born to women who received the standard treatment $[(3,223 \mathrm{~g}$ vs 3,092 g), $\mathrm{F}(1,121)=4.210, \mathrm{p}=0.042]$ among anaemic women $(\mathrm{Hb}<9.0 \mathrm{~g} / \mathrm{dL})$ and/or iron-deficient women (serum ferritin $<35 \mu \mathrm{g} / \mathrm{L}$ ). Among women who were iron-sufficient (serum ferritin $\geq 35 \mu \mathrm{g} / \mathrm{L}$ ) at recruitment, the adjusted mean birthweight in the iron-zinc supplemented group was not different from that of the control group $[(3,032 \mathrm{~g}$ vs $3,053 \mathrm{~g})$, $\mathrm{F}(1,94)=0.762, \mathrm{p}=0.762]$.

There was no significant difference in the mean length of gestation between the study groups even after adjusting for the main determinants. The mean length of gestation in the iron-zinc and the control group were $37.1 \pm 1.8$ and $37.2 \pm 1.7$ respectively $[\mathrm{F}(1,541)=0.144, \mathrm{p}=0.704]$. The other adverse pregnancy outcomes and the risk of the event occurring in the iron-zinc compared to the standard treatment group are shown in Table 2.

\section{Determinants of birthweight}

Determinants of birthweight in the whole sample and among iron-deficient and iron-sufficient women are shown separately in Table 3, 4, and 5 respectively. Variables entered in the regression analysis included malarial infection in early pregnancy, maternal age, type of treatment, use of sulphadoxine pyremethamine, and gravidity but these were excluded from the model for the whole sample because of their weak association with birthweight. This set of predictors in the separate models for birthweight explained $43.6 \%$ and $54.9 \%$ of variation in birthweight among iron-deficient and ironsufficient women respectively. Malarial infection in early pregnancy was an important determinant of birthweight only among iron-sufficient women. Preterm delivery was not an important determinant of birthweight among iron-sufficient women but it was important among iron-deficient women. Type of supplement was an important determinant of birthweight among iron-deficient but not among iron-sufficient women. Among iron-

\begin{tabular}{|c|c|c|c|c|c|c|}
\hline \multirow{2}{*}{ Outcome } & \multicolumn{2}{|c|}{$\begin{array}{l}\text { Iron-zinc group } \\
\quad(\mathrm{n}=272)\end{array}$} & \multicolumn{2}{|c|}{$\begin{array}{l}\text { Control group } \\
\quad(\mathrm{n}=271)\end{array}$} & \multirow[t]{2}{*}{ Relative risk } & \multirow[t]{2}{*}{$95 \% \mathrm{CI}$} \\
\hline & No & $\%$ & No & $\%$ & & \\
\hline Total LBW & 26 & 9.6 & 21 & 7.7 & 1.23 & $0.71,2.14$ \\
\hline Term LBW & 12 & 5.2 & 8 & 3.4 & 2.84 & $0.69,11.75$ \\
\hline Preterm delivery with LBW & 14 & 35.0 & 13 & 33.3 & 1.16 & $0.37,3.62$ \\
\hline Total IUGR & 14 & 5.1 & 18 & 6.6 & 0.78 & $0.39,1.53$ \\
\hline Preterm delivery & 40 & 14.7 & 39 & 14.4 & 1.02 & $0.68,1.54$ \\
\hline
\end{tabular}




\begin{tabular}{|c|c|c|c|c|c|c|}
\hline \multirow[t]{2}{*}{ Determinant } & \multicolumn{2}{|c|}{$\begin{array}{c}\text { Unstandardized } \\
\text { coefficients }\end{array}$} & \multirow{2}{*}{$\begin{array}{l}\text { Standardized } \\
\text { coefficients } \\
\text { beta }\end{array}$} & \multirow[t]{2}{*}{$T$} & \multirow[t]{2}{*}{$\mathrm{p}$ value } & \multirow[t]{2}{*}{$95 \%$ CI for $B$} \\
\hline & $B$ & SE & & & & \\
\hline (Constant) & -0.923 & 0.529 & & -1.745 & 0.082 & $-1.963,0.116$ \\
\hline Maternal age of participant & -0.007 & 0.004 & -0.078 & -2.009 & 0.045 & $-0.014,0.001$ \\
\hline $\begin{array}{l}\text { Diastolic pressure at } 36 \text { weeks } \\
\text { gestation }\end{array}$ & -0.003 & 0.002 & -0.070 & -2.115 & 0.035 & $-0.006,0.001$ \\
\hline Gender of baby & -0.108 & 0.031 & -0.111 & -3.471 & 0.001 & $-0.169,-0.047$ \\
\hline Intrauterine growth restriction & -0.816 & 0.068 & -0.395 & -11.981 & 0.001 & $-0.950,-0.683$ \\
\hline Length of gestation & 0.103 & 0.014 & 0.361 & 7.478 & 0.001 & $0.076,0.129$ \\
\hline Proxy socioeconomic class & 0.133 & 0.038 & 0.114 & 3.500 & 0.001 & $0.058,0.208$ \\
\hline Nulliparity & 0.192 & 0.040 & 0.188 & 4.780 & 0.001 & $0.113,0.271$ \\
\hline Alcohol drinking status & 0.136 & 0.048 & 0.090 & 2.833 & 0.005 & $0.042,0.231$ \\
\hline Preterm delivery & -0.191 & 0.066 & -0.138 & -2.883 & 0.004 & $-0.320,-0.061$ \\
\hline Maternal weight & 0.007 & 0.001 & 0.158 & 4.630 & 0.001 & $0.004,0.010$ \\
\hline
\end{tabular}

\begin{tabular}{|c|c|c|c|c|c|c|}
\hline \multirow[t]{2}{*}{ Variable } & \multicolumn{2}{|c|}{$\begin{array}{l}\text { Unstandardized } \\
\text { coefficients }\end{array}$} & \multirow{2}{*}{$\begin{array}{l}\text { Standardized } \\
\text { coefficients beta }\end{array}$} & \multirow[t]{2}{*}{$T$} & \multirow[t]{2}{*}{$\mathrm{p}$ value } & \multirow{2}{*}{$\begin{array}{l}\text { 95\% confi- } \\
\text { dence inter- } \\
\text { val for } ß\end{array}$} \\
\hline & B & SE & & & & \\
\hline (Constant) & 0.361 & 1.405 & & 0.257 & 0.798 & $-2.427,3.149$ \\
\hline Supplement type & -0.134 & 0.071 & -0.141 & -1.888 & 0.062 & $-0.276,0.007$ \\
\hline Maternal weight & 0.006 & 0.003 & 0.181 & 2.290 & 0.024 & $0.001,0.012$ \\
\hline $\begin{array}{l}\text { Diastolic pressure at } 36 \\
\text { weeks gestation }\end{array}$ & -0.005 & 0.004 & -0.115 & -1.420 & 0.159 & $-0.012,0.002$ \\
\hline Gender of baby & -0.139 & 0.073 & -0.146 & -1.920 & 0.058 & $-0.283,0.005$ \\
\hline IUGR & -0.978 & 0.160 & -0.473 & -6.121 & 0.001 & $-1.295,-0.661$ \\
\hline Length of gestation & 0.085 & 0.037 & 0.270 & 2.294 & 0.024 & $0.011,0.158$ \\
\hline Preterm delivery & -0.414 & 0.162 & -0.294 & -2.561 & 0.012 & $-0.735,-0.093$ \\
\hline
\end{tabular}

\begin{tabular}{|c|c|c|c|c|c|c|}
\hline \multirow[t]{2}{*}{ Variable } & \multicolumn{2}{|c|}{$\begin{array}{l}\text { Unstandardized } \\
\text { coefficients }\end{array}$} & \multirow{2}{*}{$\begin{array}{l}\text { Standardized } \\
\text { coefficients } \\
\text { beta }\end{array}$} & \multirow[t]{2}{*}{$T$} & \multirow[t]{2}{*}{$\mathrm{p}$ value } & \multirow{2}{*}{$\begin{array}{l}\text { 95\% confidence } \\
\text { interval for } ß\end{array}$} \\
\hline & $B$ & SE & & & & \\
\hline (Constant) & -3.543 & 0.826 & & -4.290 & 0.001 & $-5.182,-1.905$ \\
\hline $\begin{array}{l}\text { Intrauterine growth } \\
\text { restriction }\end{array}$ & -0.857 & 0.111 & -0.527 & -7.691 & 0.001 & $-1.078,-0.636$ \\
\hline $\begin{array}{l}\text { Gestational age in } \\
\text { weeks at delivery } \\
\text { Malarial infection at }\end{array}$ & 0.192 & 0.021 & 0.613 & 8.934 & 0.001 & $0.149,0.234$ \\
\hline $\begin{array}{l}\text { Malarial infection at } \\
\text { recruitment }\end{array}$ & -0.268 & 0.093 & -0.191 & -2.867 & 0.005 & $-0.453,-0.083$ \\
\hline
\end{tabular}

deficient women, women who received standard treatment, i.e. iron-only, gave birth to babies whose mean birthweight was 0.141 standard units lower than women who received the ironzinc supplement.
Effect of iron-zinc supplementation on maternal zinc and iron status

The geometric mean concentrations of plasma zinc at recruitment and at 34-36 weeks of gestation 
were $26.3 \pm 2.5 \mu \mathrm{g} / \mathrm{dL}$ (95\% confidence interval [CI] 24.1-28.6) and 40.1 $\pm 2.7 \mu \mathrm{g} / \mathrm{dL}$ (95\% CI 32.5-49.4) respectively. Treatment effect was different depending on the maternal zinc status at recruitment in the subgroup of the participants for whom plasma zinc was assessed. Adjusted for amount of supplement consumed, a strong interaction between the maternal zinc status and the type of supplement modified the treatment effect on geometric plasma zinc at $34-36$ weeks $[\mathrm{F}(1,81)=4.765, \mathrm{p}=0.032]$. Consequently, among women who had low concentrations of plasma zinc at baseline, the adjusted geometric mean plasma zinc in the iron-zinc group was higher than that in the control group, although not significant [(41.2 $\mu \mathrm{g} / \mathrm{dL}$ vs $31.2 \mu \mathrm{g} / \mathrm{dL})$, $\mathrm{F}(1,56)=1.103, \mathrm{p}=0.298]$. The geometric mean concentration of plasma zinc was adjusted for IUGR, z-score plasma zinc concentrations at recruitment, and maternal age. Among women who were not zinc-deficient (plasma zinc $\geq 60 \mu \mathrm{g} / \mathrm{dL}$ ) at recruitment, the adjusted geometric mean concentrations of plasma zinc at 34-36 weeks of gestation tended to be higher in the iron-zinc group compared to the control group [(69.8 $\mu \mathrm{g} / \mathrm{dL}$ vs $44.4 \mu \mathrm{g} / \mathrm{dL}), \mathrm{F}$ $(1,22)=2.236, p=0.149]$. Women with low levels of plasma zinc $(<60.0 \mu \mathrm{g} / \mathrm{dL})$ at recruitment also had significantly higher $\mathrm{Hb}$ compared to women who had relatively higher plasma concentrations at recruitment.

The adjusted geometric mean plasma zinc at 3436 weeks of gestation was higher among women who had normal concentrations of plasma zinc $(\geq 60 \mu \mathrm{g} / \mathrm{dL}$ ) compared to women who were zincdeficient in early pregnancy [ $(88.7 \mu \mathrm{g} / \mathrm{dL}$ vs 28.9 $\mu \mathrm{g} / \mathrm{dL}), \mathrm{F}(1,82)=10.010, \mathrm{p}=0.002)]$. Geometric concentrations of plasma zinc were adjusted for IUGR and z-score plasma zinc concentrations at baseline, gender.

\section{Relationship of maternal plasma zinc with iron status parameters}

The relationships between the maternal zinc status and the iron status indicators were assessed in a subsample of the study participants. Women who had low levels of plasma zinc $(<60.0 \mu \mathrm{g} / \mathrm{dL})$ at recruitment had also significantly higher $\mathrm{Hb}$ but lower serum ferritin and iron concentrations compared to women with normal values ( $\geq 60 \mu \mathrm{g} / \mathrm{dL}$ ). Concentrations of plasma zinc in early pregnancy positively correlated with serum ferritin ( $\mathrm{r}=0.137$, $\mathrm{p}=0.069)$ and serum iron ( $\mathrm{r}=0.261, \mathrm{p}=0.001)$. Concentrations of plasma zinc correlated negatively with $\mathrm{Hb}(\mathrm{r}=-0.165, \mathrm{p}=0.001)$ in early pregnancy.

\section{DISCUSSION}

The uniqueness of this study lies in the fact that, although previous supplementation studies involving zinc have included iron, these nutrients have not been administered as a single supplement as was done in this study. To minimize the possible absorptive competitions between iron and zinc, they were administered in a 1:1 ratio and was taken every other day and not every day.

Additionally, this study is different from other zinc trials in that, the interaction effect between supplements administered and high maternal iron $/ \mathrm{Hb}$ status was isolated making it clear that combined supplementation of iron and zinc is potentially beneficial among iron-deficient and/or anaemic but not iron-sufficient or non-anaemic women. This study recognized that failure to control for the numerous confounding factors on birthweight and the interaction effect between the maternal iron status and zinc may mask the efficacy of iron-zinc supplementation. Therefore, important prognostic variables, including malarial infection, were assessed at recruitment and in late pregnancy.

Maternal iron status in early pregnancy interacted substantially with the combined iron-zinc supplement on the mean birthweight, change in the mean plasma zinc, the mean $\mathrm{Hb}$, and geometric mean concentrations of serum ferritin at 34-36 weeks of gestation. The presence of interaction implied that the efficacy of iron-zinc supplementation was different and dependent on the iron status at recruitment. Generally, iron-zinc supplementation was effective among women who were anaemic and/or iron-deficient at recruitment.

\section{Effect of iron-zinc supplementation on mean birthweight}

Overall, there was no detectable difference in the mean birthweight between the study groups. Iron status indicators, i.e. serum ferritin and $\mathrm{Hb}$, interacted substantially with a combined iron and zinc supplement on the mean birthweight. The investigators suspected that treatment effect of iron-zinc supplementation would be different for women with different iron stores because several studies have reported high maternal iron stores and, especially when supplemented with iron during pregnancy, resulted in adverse pregnancy outcomes (27-30). The presence of interactions implied adjustment for confounding was contra-indicated. Whenever interaction is present, strata-specific estimates, instead of summary measures of association and effects, are to be reported (26). 
Efficacy of iron-zinc supplementation was higher among women who were iron-deficient. Zinc-only supplementation has not demonstrated any positive effect on pregnancy outcomes in some studies, and one may wonder why iron-zinc supplementation would result in a higher birthweight whereas zinc alone does not. One possible reason for the negative results in many studies may be due to the fact that most studies that investigated the effect of zinc-only supplementation on birthweight did not explore the interaction effect of maternal iron status on treatment effect. Failure to control the interaction effect of maternal iron status may lead to a conclusion of no effect. For instance, the study by Caulfield and colleagues in Peru did not test for interaction/antagonism between the maternal iron status and the zinc supplements administered (31). Indeed, a failure to recognize and report interaction, if it exists, is a missed opportunity to note differences in outcomes, or associations, between subgroups in the study.

Other explanations for the high efficacy of combined iron and zinc compared to iron-only supplementation among iron-deficient women may be that absorption of iron would have improved through the reductive effect of zinc on infections, such as malaria which is reported to be endemic in the study area. Second, zinc promotes the formation of insulin-like growth factor-1 (IGF-1) which, together with erythropoietin, are required for haematopoiesis $(32,33)$. These processes are essential for normal foetal growth.

Another possible explanation for the improvement in the mean birthweight among anaemic women who received iron-zinc supplementation may relate to an efficient supply of oxygen to the foetus. Oxygen is needed for the normal development of the placenta and for the release of growth hormones from the placenta and that the size of the placenta has an inverse relationship to maternal haemoglobin level (34). The synthesis of IGF-1 has been reported to be facilitated by glucose (35), and its action is potentiated by the presence of zinc (36). Although maternal IGF-1 does not cross the placenta and, therefore, does not have a direct effect on foetal growth, it may facilitate exchange of nutrient and oxygen between the placenta and the foetus.

The inability of iron-zinc supplementation to increase the mean birthweight among the iron-sufficient women in this study is not an isolated case. Several studies have earlier demonstrated poor pregnancy outcomes with high $\mathrm{Hb}(29,30)$, and it has been suggested that there may be underlying causes other than the high $\mathrm{Hb}$ that may be responsible for this association (37). One possible reason why there was no treatment effect among the ironsufficient women may be increased blood viscosity, resulting from iron-induced macrocytosis (38). An exponential or linear relationship between high $\mathrm{Hb}$ and blood viscosity is well-established (39). High $\mathrm{Hb}$ per se may not cause blood viscosity but it may serve as an indicator of high blood viscosity. A number of factors, including pre-eclampsia, are reported to limit expansion of plasma volume with the resultant high $\mathrm{Hb}$ concentrations (40).

Similar studies carried out in Peru, Nepal, and Bangladesh have reported no association between prenatal maternal zinc supplementation and mean birthweight $(31,41,42)$. Evidence from this and the Peruvian and the Nepalese studies concluded, overall, that there was no effect of iron-zinc supplementation on birthweight. Further analysis of data in this study, however, showed that the effect of iron-zinc supplementation was masked by a strong interaction between the type of supplement and the iron status of participants at recruitment. Assessing the efficacy of iron-zinc supplementation needs to take into consideration the iron status of participants at baseline. It is worth mentioning that when women with low concentrations of plasma zinc were selected during data analyses, there was still no demonstrable efficacy of iron-zinc supplementation. This may be attributed to the fact that most women with low concentrations of plasma zinc also had high $\mathrm{Hb}$ concentrations. Given the obvious interaction between zinc supplement and maternal $\mathrm{Hb}$ level, the efficacy of iron-zinc supplementation on birthweight among women with high $\mathrm{Hb}$ will naturally be reduced.

The fact that marginal iron and zinc deficiencies co-existed in this study population presupposed correcting one deficiency without the other may not have made the desired impact on pregnancy outcomes. Furthermore, iron-zinc supplementation was effective in improving the mean birthweight among iron-deficient women. It may, therefore, be inferred that zinc deficiency was an important limiting factor and, therefore, correction of iron deficiency alone in this study population was unlikely to improve birthweight. As shown in several studies $(43,44)$, iron-only supplementation is unlikely to increase birthweight.

Combined iron and zinc may be an appropriate strategy for increasing the mean birthweight, especially among iron-deficient women. Improved 
zinc status is a potential factor which could have influenced foetal growth in the subgroup of ironzinc deficient women. Supplementation of zinc is reported to increase IGF-1 in Japanese pregnant women, which was positively associated with birthweight $(\mathrm{r}=0.404, \mathrm{p}<0.05)(45)$. Zinc plays a central role in cellular growth and development during pregnancy through its influence on the growth hormone and the enzyme system that regulate cell division (46-49). The increased mean birthweight among iron-deficient women confirms some earlier observations that women with serum ferritin of less than $35 \mu \mathrm{g} / \mathrm{L}$ during pregnancy is always associated with a lack of iron in bone-marrow (50), and the possible association with zinc deficiency (51) may, therefore, better respond to iron-zinc supplementation.

\section{Effect of iron and zinc supplementation on LBW, IUGR, and preterm delivery}

This study showed that iron-zinc supplementation tended to be protective of the risk of IUGR (relative risk $[\mathrm{RR}]=0.78$; 95\% CI: 0.39-1.53) but had no effect on preterm delivery. In the adjusted logistic regression model (enter method), iron-zinc supplementation still remained weakly protective of IUGR (odds ratio $[\mathrm{OR}]=0.84$, CI 0.40-1.78). The variables adjusted for were: gravidity, height, and diastolic pressure at 34-36 weeks of gestation. The association was, however, not statistically significant at a 5\% significance level.

Overall, iron-zinc supplementation was associated with an insignificant increased risk of LBW $(\mathrm{RR}=1.23 ; 95 \% \mathrm{CI} 0.71-2.14)$. There was also no apparent effect of iron-zinc supplementation on preterm delivery in the study. The protective role of zinc supplementation on IUGR and preterm delivery has been inconsistent. As candidly submitted by de Onis et al (52), benefits from zinc supplementation can only be realized in zinc-deficient populations. While some studies have found low maternal plasma zinc to be a risk factor for preterm delivery (53), others did not $(54,55)$. Some zinc-supplementation trials had a positive effect on preterm delivery (56-58).

Effect of combined iron and zinc supplementation on maternal iron and zinc status

In view of the unreliability of concentrations of plasma zinc as an indicator of zinc nutriture, changes in the mean concentrations of plasma zinc, i.e. responsiveness, to iron-zinc supplementation may better reflect iron and zinc deficiency than any one-time measurement in a given population. However, response to iron-zinc supplementation was also greatly influenced by some interactions between the supplement administered and the maternal iron and zinc status.

Anaemia at recruitment, which is a measure of iron status and also a reflection of end-stage iron deficiency, interacted substantially with the treatment on a number of outcomes, including geometric mean concentrations of plasma zinc at 34-36 weeks of gestation, birthweight, mean change in $\mathrm{Hb}$, and mean concentrations of serum ferritin in late pregnancy. Generally, iron-zinc supplementation was effective among women who were anaemic and/or iron-deficient at recruitment.

Selection of women for iron-zinc supplementation based on low concentrations of plasma zinc alone may also be inadequate because this group of women was found to have high $\mathrm{Hb}$ concentrations. Women of concurrent marginal zinc deficiency and high $\mathrm{Hb}$ may not respond adequately to iron-zinc supplementation because of the strong effect modification exerted by their iron status in early pregnancy on birthweight, plasma zinc, and $\mathrm{Hb}$. Women with low plasma zinc and concurrent $\mathrm{Hb}$ less than $9.0 \mathrm{~g} / \mathrm{dL}$ demonstrated the greatest potential of benefiting maximally from iron-zinc supplementation. The treatment effect on maternal zinc response was observed mainly among women with low $\mathrm{Hb}$.

A pertinent question one is tempted to ask is 'was high $\mathrm{Hb}$ a cause for lack of efficacy with iron-zinc supplementation or is it an indicator of some underlying cause'? High $\mathrm{Hb}$ may result from increased red cell mass as a compensatory response to inadequate oxygen supply to tissues or as a result of inadequate plasma volume expansion (39). Indeed, inadequate oxygen supply and poor plasma volume expansion have the potential of limiting foetal growth.

The prevalence of low concentrations of plasma zinc in the subsample was strikingly high and may be attributed to a number of factors. Aside poorquality diets, a number of factors, such as infections, not necessarily relating to nutritional zinc status, may have influenced plasma zinc levels. Low concentrations of plasma zinc during pregnancy may not necessarily reflect zinc deficiency as infections $(59,60)$, haemodilution, and other metabolic changes can contribute to low zinc levels (61). These factors, therefore, further complicate the diagnosis and interpretation of real zinc deficiency 
during pregnancy and in assessing the efficacy of iron-zinc supplementation.

\section{Relationship between plasma zinc and iron} status parameters

There were strong relationships between the maternal zinc status and the iron status indicators, i.e. $\mathrm{Hb}$ and serum iron, in early pregnancy. Women with low levels of plasma zinc had also high concentrations of $\mathrm{Hb}$ at recruitment. Of the 114 women who were iron-deficient at recruitment, $88.6 \%(101 / 114)$ also had low concentrations of zinc. There was, therefore, a strong association between maternal zinc and the iron status in this study population; a relationship that has also been consistently shown in the United States $(15,62)$.

Women with low levels of $(<60.0 \mu \mathrm{g} / \mathrm{dL})$ plasma zinc at recruitment also had significantly higher $\mathrm{Hb}$ but lower serum ferritin and iron concentrations compared to women with normal values ( $\geq 60 \mu \mathrm{g}$ / $\mathrm{dL}$ ). Although a negative relationship between plasma zinc and $\mathrm{Hb}$ in early pregnancy was observed in this study, a study among pregnant Malawian women reported lack of correlation between serum zinc and $\mathrm{Hb}$ (63).

What are the possible explanations for the negative association between $\mathrm{Hb}$ and plasma zinc levels in early pregnancy observed in this study?

One possible mechanism that may help explain the negative relationship between plasma zinc and $\mathrm{Hb}$ concentrations in this study is that low plasma zinc may be associated with inadequate expansion of plasma volume and, therefore, little haemodilution effect and subsequent high $\mathrm{Hb}$. Poor nutritional profile in early pregnancy is positively associated with reduced plasma volume $(64,65)$, and it is possible that low concentrations of plasma zinc were partly reflective of the poor nutritional status of women. The high $\mathrm{Hb}$ may also be a reflection of inadequate plasma volume expansion, vis-à-vis increased red cell mass that had taken place.

Additionally, increased foetal erythropoiesis may result in reduced plasma zinc but stimulate maternal erythropoiesis with a resultant increase in maternal $\mathrm{Hb}$.

It is concluded that combined prenatal iron and zinc compared to iron-only supplementation was more effective in increasing the mean birthweight among iron-deficient women but not among women with elevated iron stores in early pregnancy. There was no discernible diference in the mean birthweight between the study groups among women who were iron-sufficient in early pregnancy.

Interaction reduces efficacy, and this must be recognized and isolated in all future supplementation studies involving iron and zinc. Additionally, early detection of high levels of serum ferritin in pregnant women should alert health workers to critically examine such clients for a possibility of infections and/or reduce the dosage of prescribed iron supplements. The findings also bring to fore the need for adequate laboratory facilities for the routine diagnosis of serum ferritin levels in health institutions.

\section{ACKNOWLEDGEMENTS}

The authors acknowledge the financial support provided by the Public Health Research Group (PHRG) of Edith Cowan University (ECU) to procure iron-zinc supplements and weighing scales for this research. The authors also acknowledge the contribution by the midwives of the Antenatal Unit and the Labour Ward of the Wa Regional Hospital in Ghana, whose organization and cooperation made it possible to recruit pregnant women for the study. They were also actively involved in monitoring of compliance and collection of data. The authors extend warmest compliments to all the pregnant women who participated in the study for their immense cooperation. The authors also sincerely acknowledge the zeal and support received from Tony Basingnaa and Theresa Salifu, both from the Wa Regional Hospital Laboratory for the blood sample collection and diagnosis of some blood disorders, especially HIV infections and anaemia.

\section{REFERENCES}

1. Ghana. Upper West Regional Health Directorate. Annual report. Wa: Ghana Health Service-Upper West Region, 2004:73.

2. Arifeen SE, Black RE, Caulfield LE, Antelman G, Baqui $\mathrm{AH}, \mathrm{Nahar} \mathrm{Q}$ et al. Infant growth patterns in the slums of Dhaka in relation to birth weight, intrauterine growth retardation, and prematurity. Am J Clin Nutr 2000;72:1010-7.

3. Kalanda BF, van Buuren S, Verhoeff FH, Brabin BJ. Catchup growth in Malawian babies, a longitudinal study of normal and low birthweight babies born in a malarious endemic area. Early Hum Dev 2005;81:841-50.

4. Motta MEFA, da Silva GAP, Araújo OC, LiraI PI, Marília de Carvalho Lima. Does birth weight affect nutritional status at the end of first year of life? J Pediatr 2005;81:377-82. 
5. Olinto MT, Victora CG, Barros FC, Tomasi E. Determinants of malnutrition in a low-income population: hierarchical analytical model Cad Saude Publ 1993;9(Suppl 1):S14-27.

6. Kramer MS. Intrauterine growth and gestational duration determinants. Pediatrics 1987;80:502-11.

7. McCormick MC. The contribution of low birth weight to infant mortality and childhood mortality. N Engl J Med 1985;312:82-90.

8. Barker DJP, Fall CHD. The immediate and long-term consequences of low birthweight. Technical Consultation on Low Birthweight. New York, NY: United Nations Children's Fund, 2000:17.

9. de Onis M, Blossner M, Villar J. Levels of intrauterine growth retardation in developing countries. Eur J Clin Nutr 1998;52:S5-S15.

10. ACC/SCN. Nutrition and the Millennium Development Goals. SCN News 2004;28:5-35.

11. Ramakrishnan U, Imhoff-Kunsch B. Anemia and iron deficiency in developing countries In: LammiKeefe CJ, Couch SC, Philipson EH, editors. Handbook of nutrition and pregnancy. Totowa: Humana Press, 2008:337-54.

12. Menendez C, Ordi J, Smail MR, Ventura PJ, Aponte JJ, Kahigwa E et al. The impact of placental malaria on gestational age and birth weight. J Infect Dis 2000;181:1740-5.

13. Hotz C, Brown KH. Assessment of the risk of zinc deficiency in populations and options for its control: technical document 1 by International Zinc Nutrition Consultative Group (IZiNCG). Food Nutri Bull 2004;(Suppl 2):S91-S204.

14. Black RE, Sazawal S. Zinc and childhood infectious diseases: morbidity and mortality. Br J Nutr 2001;85(Suppl 2):S125-S29.

15. Yokoi K, Alock N, Sandstead H. Iron and zinc nutriture of premenopausal women: associations of diet with serum ferritin and plasma zinc disappearance, and of serum ferritin with plasma zinc and plasma zinc disappearance. J Lab Clin Med 1994;124:852-61.

16. International Zinc Nutrition Consultative Group. Assessment of the risk of zinc deficiency in populations and options for its control. Food Nutr Bull 2004;25: S91-204.

17. Dijkhuizen MA, Wieringa FT. Vitamin A, iron and zinc deficiency in Indonesia: micronutrient interactions and effects of supplementation. Wageningen: Wageningen University, 2001. (PhD thesis).

18. Williams RL, Creasy RK, Cunningham GC, Hawes WE, Norris FD, Tashiro M. Fetal growth and perinatal viability in California. Obstet Gynecol 1982;59:624-32.

19. Lewis SM, Bain BJ, Bates I. Dacie and Lewis Practical haematology. 9th ed. New York, NY: Churchill Livingstone, 2001:19-23.
20. Daniel HR. Examination of blood. In: Beutler E, Lichtman MA, Coller BS, Kipps T, Seligsolin URI, editors. Williams Hematology. 6th ed. New York, NY: McGraw Hill Medical Publishing Division, 2001:9-16.

21. Abbott AxSYM Laboratories. AxSYM ferritin assay for the quantitative determination of ferritin in human serum or plasma. Illinois, IL: Abbott AxSYM Laboratories, 2005.

22. Lippo H, Sarkela A. Microwave dissolution methods for the determination of heavy metals in biomonitors using GFAAS and flame AAS. At Spectrosc 1995;16:154-7.

23. Abbott Laboratories. User's manual for determining HIV 1/2. Illinois, IL: Abbott Laboratories, 2002:1-15.

24. Friedman LM, Furberg CD, Demets DL. Sample size. In: Fundamentals of clinical epidemiology. New York, NY: Mosby, 1996:94-125.

25. Woodward M. Epidemiology: study design and data analysis. 2nd ed. New York, NY: Chapman \& Hall, 2004:381.

26. Gerstman BB. Binary outcome, stratified analysis. In: Data analysis with Epi-Info. 2000. (www.sjsu.edu/faculty/gerstman/EpiInfo/stratified.htm, accessed on 24 October 2007).

27. Ronnenberg AG, Wood RJ, Wang X, Xing H, Chen C, Chen $\mathrm{D}$ et al. Preconceptional hemoglobin and ferritin concentrations are associated with pregnancy outcome in a prospective cohort of Chinese women. J Nutr 2004;134:2586-91.

28. Steer PJ. Maternal haemoglobin concentration and birth weight. Am J Clin Nut 2000;71:1285S-7S.

29. Murphy JF, O’Riordan J, Newcombe RG, Coles EC, Pearson JF. Relations of hemoglobin levels in first and second trimesters to outcome of pregnancy. Lancet 1986;1:992-5.

30. Lu ZM, Goldenburg RL, Cliver SP, Cutter G, Blankson ML. The relationship between maternal hematocrit and pregnancy outcome. Obstet Gynecol 1991;71:190-4.

31. Caulfield LE, Zavaleta N, Figueroa A, Leon Z. Maternal zinc supplementation does not affect size at birth or pregnancy duration in Peru. J Nutr 1999;129:1563-8.

32. Lely AJ, Lamberts SWJ. Increase in haemoglobin concentrations in growth hormone deficient adults during human recombinant growth hormone replacement therapy. Clin Endocrinol 1997;47:565-70

33. Vihervuori E, Virtanen M, Koistinen H, Koistinen R, Seppälä M, Siimes MA. Hemoglobin level is linked to growth hormone-dependent proteins in short children. Blood 1996;87:2075-81.

34. Godfrey KM, Redman CW, Barker DJP, Osmond C. The effect of maternal anaemia and iron deficiency on the ratio of fetal weight to placental weight. BJOG 1991;98:886-91. 
35. Halvorsen S, Bechensteen AG. Physiology of erythropoietin during mammalian development. Acta Paediatr 2002;438(Suppl):17-26.

36. Matsui T, Yamaguchi M. Zinc modulation of insulinlike growth factor's effect in osteoblastic MC3T3-E1 cells. Peptides 1995;16:1063-8.

37. Yip R. Significance of an abnormally low or high hemoglobin concentration during pregnancy: special consideration of iron nutrition. Am J Clin Nutr 2000;72:272S-9S.

38. Koller $\mathrm{O}$. The clinical significance of hemodilution during pregnancy. Obstet Gynecol Surv 1982;37:649-52.

39. Erslev AJ. Secondary polycythemia (erythrocytosis). In: Williams WJ, Butler E, Erslev AJ, Lichtman MA, editors. Hematology. 3rd ed. New York, NY: McGrawHill, 1983:673-84.

40. Pritchard JA, Cunningham FG, Pritchard SA. The Parkland Memorial Hospital protocol for treatment of eclampsia: evaluation of 245 cases. Am J Obstet $G y$ necol 1984;148:951-63.

41. Christian P, Khatry SK, Katz J. Effects of alternative maternal micronutrient supplements on low birth weight in rural Nepal: double blind randomised community trial. BMJ 2003;326:571-6.

42. Osendarp SJ, van Raaij JMA, Arifeen SE, Whed MA, Baqui AK, Fuchs GJ. A randomized, placebo-controlled trial of the effect of zinc supplementation during pregnancy on pregnancy outcome in Bangladeshi urban poor. Am J Clin Nutr 2000;71:114-9.

43. Rasmussen KM. Is there a causal relationship between iron deficiency anaemia and weight at birth, length of gestation and perinatal mortality? Am J Clin Nut 2001;131:590-603S.

44. Routine iron supplementation during pregnancy. Policy statement. U.S. Preventive Services Task Force. JAMA 1993;270:2846-8.

45. Nishiyama S, Okada T, Kiwaki K, Miyazaki Y, Hasuda T. Effect of zinc administration on IGF-1, hemoglobin and birth weight of newborn in pregnant women. Clin Pediar Endocrinol 2000;9:75-81.

46. MacDonald RS. The role of zinc in growth and cell proliferation. J Nutr 2000;130:1500S-8S.

47. Basset NS, Oliver MH, Breier BH, Gluckman PD. The effect of maternal starvation on plasma insulin-like growth factor I concentration in the late gestation ovine fetus. Pediatr Res 1990;27:401-4.

48. Simmer K, Thompson RP. Zinc in the fetus and newborn. Acta Paediatr Scand 1985;319(Suppl):158-63.

49. Spencer JAD, Chang TC, Jones J. Third trimester foetal growth and umbilical venous blood concentrations of IGF-1, IGFBP-1, and growth hormone at term. Arch Dis Child 1995;73:F87-90.

50. Puolakka J. Serum ferritin as a measure of iron stores during pregnacy. Acta Obstet Gynecol Scand 1980;95(Suppl):1-63.

51. Nishiyama S, Kiwaki K, Miyazaki Y, Hasuda T. Zinc and IGF-1 concentration in pregnant women with anaemia before and after supplementation with iron and/or zinc. J Am Coll Nutr 1999;18:261-7.

52. de Onis M, Villar J, Gulmezoglu AM. Nutritional interventions to prevent intrauterine growth retardation:evidence from randomized controlled trials. Eur J Clin Nutr 1998;52:S83-93.

53. Sikorski R, Juszkiewicz T, Paszkowski T. Zinc status in women with premature rupture of membranes at term. Obstet Gynecol 1990;76:675-7.

54. Islam M, Hemalatha P, Bhaskaram P, Kumar P. Leukocyte and plasma zinc in maternal and cord blood: their relationship to period of gestation and birth weight. Nutr Res 1994;14:353-60.

55. Tamura T, Goldenberg RL, Johnston KE, DuBard MB. Maternal plasma zinc concentrations and pregnancy outcome. Am J Clin Nutr 2000;71:109-13.

56. Cherry F, Sandstead H, Rojas P, Johnson L, Batson H, Wang X. Adolescent pregnancy: associations among body weight, zinc nutriture, and pregnancy outcome. Am J Clin Nutr 1989;50:945-54.

57. Garg HK, Singhal KC, Arshad Z. A study of the effect of oral zinc supplementation during pregnancy on pregnancy outcome. Indian J Physiol Pharmacol. 1993;37:276-84.

58. Castillo-Duran C, Marin V, Alcazar L, Iturralde H, Ruz M. Controlled trial of zinc supplementation in Chilean pregnant adolescents. Nutr Res 2001;21:715-24.

59. Singh A, Smoak BL, Patterson KY, LeMay LG, Veillon C, Deuster PA. Biochemical indices of selected trace minerals in men: effect of stress. Am J Clin Nutr 1991;53:126-31.

60. Brown KH. Effect of infections on plasma zinc concentration and implications for zinc status assessment in low-income countries. Am J Clin Nutr 1998;68:425S-9S.

61. Agett P, Favier A. Zinc. Int J Vit Nutr Res 1993;63:301.

62. Sandstead HH, Darnell LS, Alcock NW. Association of iron and zinc nutriture (abstract). FASEB J 1991;5: A1291.

63. Gibson RS, Huddle JM. Suboptimal zinc status in pregnant Malawian women: its association with low intakes of poorly available zinc, frequent reproductive cycling, and malaria. Am J Clin Nut 1998;67:702-9.

64. Rosso P, Salas SP. Mechanisms of fetal growth retardation in the underweight mother. Adv Exp Biol Med 1994;352:1-9.

65. Scholl TO. High third-trimester ferritin concentration: associations with very preterm delivery, infection, and maternal nutritional status. Obstet Gynecol 1998;92:161-6. 